\title{
Randomised observer blind comparative trial of ceftriaxone and penicillin in treating uncomplicated ed gonorrhoea in men and women
}

\author{
C A DIXON,* J B BITTINER,* M SHAHIDULLAH, $\dagger$ R C B SLACK, $\ddagger$ AND M Z C SULAIMAN* \\ From the Departments of Genitourinary Medicine. ${ }^{*}$ General Hospital, Nottingham, and + County Hospital, Lincoln. \\ and $\ddagger$ Department of Microbiology and Public Health Laboratory Service Laboratory. Queen's Medical Centre. \\ Nottingham
}

SUMMARY Ceftriaxone is a third generation cephalosporin with a prolonged half life. It was used in doses of $500 \mathrm{mg}$ intramuscularly in $27 \mathrm{men}$ (group 1) and 23 women (group 2) and $250 \mathrm{mg}$ in $48 \mathrm{men}$ (group 3) and 45 women (group 4) with uncomplicated urogenital gonorrhoea. Similar numbers of patients in each group were treated with 2 MIU intramuscular Bicillin (procaine penicillin $1.5 \mathrm{~g}$ plus benzylpenicillin $300 \mathrm{mg}$ (Brocades, Weybridge, Surrey, England).

Success of treatment was measured as one or two negative cultures after three or more days. The success rate for ceftriaxone was $100 \%$ in 19 evaluable men and 19 women treated with $500 \mathrm{mg}$ and in 38 men and 31 women treated with $250 \mathrm{mg}$, including one infection due to penicillinase producing Neisseria gonorrhoeae (PPNG).

Success rates for Bicillin were $90 \%(19 / 21)$ evaluable patients cured in group $1,100 \%(19 / 19)$ in group 2, 95\% (37/39) in group 3, and 92\% (33/36) in group 4. Both drugs were well tolerated. Each isolate of $N$ gonorrhoeae isolated was sensitive to $0.05 \mathrm{mg} / \mathrm{l}$ or less of ceftriaxone.

\section{Introduction}

Ceftriaxone would seem to fulfil many of the criteria for single dose treatment of uncomplicated gonorrhoea. Its plasma half life is $6 \frac{1}{2}$ to $8 \frac{1}{2}$ hours, whereas other cephalosporins have half lives of 45 minutes to $2 \%$ hours. ' Its bioavailability is $100 \%$ when given intramuscularly, $40 \%$ being excreted in bile and $60 \%$ in urine. ${ }^{2}$ Probenecid has no effect on its excretion. ${ }^{2}$ It has an excellent safety record ${ }^{12}$ and is well tolerated by patients. ${ }^{3-5}$

In vitro its potency for both penicillinase producing Neisseria gonorrhocae (PPNG) and non-PPNG strains exceeds that of all other cephalosporins to date and of other antibiotics with which it has been compared. ${ }^{n-x}$

In vivo almost all the published trials to date have shown $100 \%$ cure rates for uncomplicated urethral, cervical, and rectal gonorrhoea caused by both PPNG and non-PPNG strains, using dosages as low as 125 mg ceftriaxone. ${ }^{3-5} 10-16$ We report our experience with ceftriaxone, comparing it with penicillin in an observer blind trial.

Address for reprints: Dr C A Dixon, Perth and Amberley House Clinics, General Hospital, Nottingham NG1 6HA

Accepted for publication 24 July 1985

\section{Patients and methods}

Patients studied attended the clinics for sexually transmitted diseases at Nottingham and Lincoln and gave informed verbal consent.

To be admitted into the trial men had to have uncomplicated urethral or rectal gonorrhoea diagnosed by the presence of Gram negative intracellular diplococci (GNICD) in smears from those sites. Swabs were taken from the urethra in heterosexual patients and from the urethra and rectum in homosexuals, and were transported in Amies' medium. $N$ gonorrhoeae was isolated on modified New York City (MNYC) medium ${ }^{17}$ with added antiboitics for non-urethral specimens. Minimum inhibitory concentrations (MICs) of penicillin and ceftriaxone for the isolates were measured by agar incorporation in MNYC medium, using reference strains IRS3 and IRS5 as controls. Strains isolated at the Public Health Laboratory, Lincoln, were sent to Nottingham for ceftriaxone testing (by courtesy of the Director, Dr $\mathrm{J} G$ Wallace). Patients in whom the initial cultures for $N$ sonorrhoeae were negative were subsequently excluded from the trial. Patients were excluded if they had received antibiotics in the previous 10 days or if they had undiagnosed genital ulcers or known renal or hepatic disease. 
Women were included if GNICD were seen on urethral, cervical, or rectal smears or $N$ gonorrhoeae was cultured from urethral, cervical, or rectal swabs. The exclusions noted for men also applied to the women. In addition pregnant women were excluded, as were those not using adequate contraception (such as the contraceptive pill, an intrauterine device, or sterilisation) and any woman with evidence of salpingitis on clinical examination.

The patients were divided into four groups according to sex and the dose of ceftriaxone used; within each group about half were treated with ceftriaxone and half with penicillin according to a computer generated randomisation schedule.

Group 1 contained 27 men who received $500 \mathrm{mg}$ ceftriaxone in $4 \mathrm{ml} \mathrm{1 \%}$ lignocaine int ramuscularly and 28 men who received 2 MIU Bicillin (Brocades, Weybridge, Surrey, England; 3 g procaine penicillin and $600 \mathrm{mg}$ benzylpenicillin sodium) in $5 \mathrm{ml} 0.5 \%$ phenol intramuscularly. Group 2 contained 23 women treated with $500 \mathrm{mg}$ ceftriaxone and 25 women receiving 2 MIU Bicillin. Group 3 contained 48 men given $250 \mathrm{mg}$ ceftria xone in $2 \mathrm{ml} 1 \%$ lignocaine and 50 men who received 2 MIU Bicillin. Group 4 contained 45 women given $250 \mathrm{mg}$ ceftriaxone as above and 46 women who received 2 MIU Bicillin.

All patients were asked to attend again two to three days after treatment and after nine days and 16 days; they were asked to abstain from sexual intercourse during this period. At the first follow up visit they were asked about symptoms, sexual activitiy, and any side effects of their treatment. At each visit smears for microscopy and material for culture were taken from the same sites as initially.

In women, infections with other organisms, such as Candida albicans, Trichomonas vaginalis, and Chlamydia rachomatis were treated 10 days after giving the trial drug. In men culture for $C$ trachomatis was not undertaken routinely, but postgonococcal urethritis (PGU), which was defined as 10 or more pus cells per high power field $(\times 1000)$ on an urethral smear without GNICD, was treated at the third follow up visit.

\section{Results}

Success of treatment was denoted by negative cultures for $N$ gonorrhoeae; ideally two negative cultures were required but some patients only attended for one follow up visit. If that visit was on day 2 they were recorded as having been lost to follow up to exclude the possibility that the infection had been suppressed but not cured at that stage. Single negative cultures on day 3 or later were recorded as "one negative culture".

Reinfection was recorded when a patient still had gonorrhoea at the first follow up visit, but admitted having had intercourse with a sexual partner who was known to be infected.

The difference in ages and symptoms between patients treated with ceftriaxone and Bicillin within each group was not significant.

Discounting unproved initial infections and patients lost to follow up, table I compares the sites of infection, incidence of PGU, and success rates with the two drugs in evaluable patients in each group. In group 1 there was a treatment failure with Bicillin in a patient with a urethral infection with a PPNG strain. One rectal infection was cured by $500 \mathrm{mg}$ ceftriaxone and one by Bicillin, the third patient being reinfected by first follow up. In group 2 both drugs were $100 \%$ successful, including treatment of three rectal infections with Bicillin. In group 3,250 mg ceftriaxone cured one case of gonorrhoea caused by a non-PPNG strain that was resistant to penicillin in vitro (MIC 0.5 $\mathrm{mg} / \mathrm{l}$ ) and a second that was caused by a PPNG strain; both had two checks of cure. The failure with Bicillin was in a patient infected with a non-PPNG strain with an MIC of $0.5 \mathrm{mg} / \mathrm{l}$ penicillin. In group 4, the failures with Bicillin were both in patients infected with nonPPNG strains with MICs of 0.1 and $0.2 \mathrm{mg} / 1$ penicillin.

The figures for adverse arug reactions, which consisted of nothing more than mild pain at the

TABL.I: I Sites of infection and results of treatment with eeftriavone $500 \mathrm{mg}$ or $250 \mathrm{mg}$ or Bicillin $2 \mathrm{MIU}$

\begin{tabular}{|c|c|c|c|c|c|c|c|c|}
\hline & \multicolumn{2}{|c|}{ Group 1 (men) } & \multicolumn{2}{|c|}{ Group 2 (women) } & \multicolumn{2}{|c|}{ Group 3 (men) } & \multicolumn{2}{|c|}{ Group 4 (women) } \\
\hline & $\begin{array}{l}\text { Ceftriaxone } \\
500 \mathrm{mg}\end{array}$ & $\begin{array}{l}\text { Bicillin } \\
2 \text { MIU }\end{array}$ & $\begin{array}{l}\text { Ceftriaxone } \\
500 \mathrm{mg}\end{array}$ & $\begin{array}{l}\text { Bicillin } \\
2 \text { MIU }\end{array}$ & $\begin{array}{l}\text { Ceftriaxone } \\
250 \mathrm{mg}\end{array}$ & $\begin{array}{l}\text { Bicillin } \\
2 \text { MIU }\end{array}$ & $\begin{array}{l}\text { Ceftriaxone } \\
250 \mathrm{mg}\end{array}$ & $\begin{array}{l}\text { Bicillin } \\
2 \text { MIU }\end{array}$ \\
\hline Evaluable patients & 19 & 21 & 19 & 19 & 38 & 39 & 31 & 36 \\
\hline Urethral infections & 18 & 19 & 16 & 13 & 38 & 38 & 20) & 24 \\
\hline Cervical infections & & & 18 & 18 & & & 31 & 34 \\
\hline Rectal infections & 1 & 2 & () & 3 & 0) & 3 & 0 & 1 \\
\hline $\begin{array}{l}\text { Two negative cultures } \\
\text { after treatment }\end{array}$ & & & & & & & & \\
\hline One negative culture & 16 & 15 & 15 & 16 & 30) & 24 & 22 & 26 \\
\hline $\begin{array}{l}\text { One negative culture } \\
\text { Post gonococeal }\end{array}$ & 3 & 4 & 4 & 3 & 8 & 13 & 9 & 7 \\
\hline urethritis ('i) & $8(42)$ & $6(28 \cdot 5)$ & & & $17(47)$ & $10(25 \cdot 6)$ & & \\
\hline Reinfections & 0 & 1 & () & () & () & 1 & 0) & 1 \\
\hline Failures & () & 1 & 0 & 0 & 0 & 1 & o & 2 \\
\hline Successes (1\%) & 100 & 90 & 100 & 100 & 100 & 95 & 100 & 92 \\
\hline
\end{tabular}


TABLE II Incidence of adverse drug reactions in total trial population

\begin{tabular}{llll}
\hline & \multicolumn{3}{c}{ Ceftriaxone } \\
\cline { 3 - 4 } \cline { 3 - 4 } & Bicillin 2MIU & $500 \mathrm{mg}$ & $200 \mathrm{mg}$ \\
\hline $\begin{array}{c}\text { Total men and } \\
\text { women treated }\end{array}$ & 149 & 50. & 93 \\
$\begin{array}{c}\text { No }(\%) \text { adverse } \\
\text { drug reactions }\end{array}$ & $25(16 \cdot 8)$ & $9(18)$ & $11(11.8)$ \\
\hline
\end{tabular}

injection site or transient gastrointestinal symptoms, were calculated from the total numbers of patients treated (table II). One man who had received $250 \mathrm{mg}$ ceftriaxone remarked that it was less painful than Bicillin, which he had received on several occasions previously.

The sensitivities to penicillin of strains of $N$ gonorrhoeae in Nottingham and Lincoln were similar to those found in a previous study. ${ }^{18}$ The MICs for organisms isolated from patients in this trial were similar to those encountered in the Public Health Laboratories at the time of the trial. The minimum concentrations that inhibited $90 \%$ of all strains were $0.5 \mathrm{mg} / \mathrm{l}$ penicillin and $0.005 \mathrm{mg} / \mathrm{l}$ ceftriaxone. Similar 100 -fold differences were found between penicillin and ceftriaxone for the $\mathrm{MIC}_{50}$ and mean concentrations. All strains of $N$ gonorrhoeae isolated were inhibited by $0.05 \mathrm{mg} / \mathrm{l}$ or less of ceftriaxone, whereas some $B$ lactamase producing strains had MICs of penicillin greater than $100 \mathrm{mg} / \mathrm{l}$.

\section{Discussion}

Ceftriaxone has shown consistently high success rates in treating uncomplicated urogenital gonorrhoea in all reports published to date; the doses used compare, in many cases, with those used to treat the gonococcus with penicillin in the early days of antibiotic treatment.

Table III summarises those trial results where ceftriaxone has been $100 \%$ successful in doses of 125 $\mathrm{mg}$ to $500 \mathrm{mg}$. At the much lower doses of $32.5 \mathrm{mg}$ and $62.5 \mathrm{mg}$ the cure rate was still $100 \%$ for urethral infections with PPNG strains; ${ }^{11}$ in non-PPNG urethral infections the cure rates were $96.2 \%$ with $62.5 \mathrm{mg} .95 \%$

TABLE III Numbers of patients treated with different doses of ceftriaxone for uncomplicated gonorrhoea with $100 \%$ success in the present and previous trials s.5 $^{30-16} 20-21$

\begin{tabular}{|c|c|c|c|c|}
\hline \multirow[b]{2}{*}{ Sites of infection } & \multirow[b]{2}{*}{ Strains } & \multicolumn{2}{|c|}{ Dose of ceftriaxone: } & \multirow[b]{2}{*}{$500 \mathrm{mg}$} \\
\hline & & $125 \mathrm{mg}$ & $250 \mathrm{mg}$ & \\
\hline \multicolumn{5}{|l|}{ Men: $:^{3} \leqslant 10,10: 1$} \\
\hline \multirow[t]{2}{*}{ Urethra } & PPNG & 19 & 80 & \\
\hline & Non-PPNG & 123 & 361 & 141 \\
\hline \multirow{2}{*}{\multicolumn{5}{|c|}{$\begin{array}{l}\text { Recium } \\
\text { Women: }\end{array}$}} \\
\hline & & & & \\
\hline Cervix 20 & Non-PPNG & & 53 & 18 \\
\hline Urethra & Non-PPNG & & 32 & 16 \\
\hline \multirow[t]{2}{*}{ Rectum } & Non-PPNG & 20 & 10 & \\
\hline & PPNG & 3 & & \\
\hline
\end{tabular}

with $50 \mathrm{mg}$, and $97.3 \%$ with $32.5 \mathrm{mg} .{ }^{11} 12$ The trial by Clay et al, however, reports the only treatment failures with a dose of $500 \mathrm{mg}$ ceftriaxone; one out of $100 \mathrm{men}$ and two out of 86 women given $500 \mathrm{mg}$ ceftriaxone were not cured. ${ }^{19}$ In the same trial five out of 109 men were not cured by $250 \mathrm{mg}$ ceftriaxone. Collier et al reported one failure in 55 cervical infections treated with $125 \mathrm{mg}$ ceftriaxone. ${ }^{20}$

Fewer cases of pharyngeal gonorrhoea have been treated; in all, published data show four out of four cures with $500 \mathrm{mg}$, six out of six cures with $250 \mathrm{mg}$, and 44 out of 48 cures with $125 \mathrm{mg}^{3}{ }^{411} 19-21$

Because of the low doses used, it was possible to use very small amounts of lignocaine diluent, thus minimising pain at the injection site without affecting the bioavailability of the drug. ${ }^{22}$ Though in our trial we used $2 \mathrm{ml}$ lignocaine for $250 \mathrm{mg}$ ceftriaxone and 4 $\mathrm{ml}$ for the $500 \mathrm{mg}$ dose, other trials have used half these amounts, with only $0.5 \mathrm{ml}$ lignocaine for $125 \mathrm{mg}$ ceftriaxone, and in some cases the injections were given into the deltoid muscle almost painlessly. ${ }^{4020} \mathrm{In}$ our trial the incidence of local pain was less with the lower dose of ceftriaxone.

We did not perform tests of liver and kidney function or full blood counts before and after treatment, but in the trials where these have been undertaken no harmful effects were noted..$^{3-5} 132021$

It is recognised that cephalosporins do not cure chlamydial infections, and other trials have shown no difference in the incidence of PGU after ceftriaxone and after spectinomycin ${ }^{3}$ or kanamycin. ${ }^{11}$ In our trial a higher incidence of PGU was noted after ceftriaxone than after Bicillin.

Another infection that may coexist with gonorrhoea is early syphilis, and ceftriaxone has been shown to be effective in treating syphilis in rabbits, ${ }^{23}$ so incubating seronegative syphilis could be aborted by single dose ceftriaxone treatment.

In the United Kingdom the incidence of infections with PPNG strains has risen yearly until 1983 (the last available date), ${ }^{24}$ but it has not yet approached $5 \%$ of all cases of gonorrhoea. If that level is reached McCutchan et al have recommended that penicillin should no longer be used as a routine treatment for gonorrhoea. ${ }^{25}$ If such a situation arose then ceftriaxone would be a suitable alternative. In the meantime, ceftriaxone is an excellent drug for treating known or suspected penicillin resistant strains.

We thank the staff of the clinics and laboratories in Nottingham and Lincoln and the pharmacists who managed the trial. We thank Roche Products Limited for providing the ceftriaxone used in this study.

This paper was presented at the spring meeting of the Medical Society for the Study of Venereal Diseases held in Uppsala. Sweden, in May 1985. 
References

1. Seddon, $\mathbf{M}$, Wise R, Gillett AP, Livingston R. Pharmacokinetics of Ro 13-9904, a broad spectrum cephalosporin. Antimicrob Agents Chemother 1980;18:240-2.

2. Stoeckel K. Pharmacokinetics of rocephin. Chemotherapy 1981;27suppl 1:42-6.

3. Handsfield HH, Murphy VL. Comparative study of ceftriaxone and spectinomycin for treatment of uncomplicated gonorrhoea in men. Lancet 1983;ii:67-70.

4. Judson FN, Ehret JM, Root CJ. Comparative study of ceftriaxone and aqueous procaine penicillin $\mathrm{G}$ in the treatment of uncomplicated gonorrhoea in women. Antimicrob Agents Chemother 1983;23:218-20.

5. Zajdowicz TR, Sanches PL, Berg SW, Kerbs SBJ, Newquist RL, Harrison WO. Comparison of ceftriaxone with cefoxitin in the treatment of penicillin resistant gonococcal urethritis. British Journal of Venereal Diseases 1983;59:176-8.

6. Prere MF, Lefevre JC, Lareng MB. Study of the in vitro activity of new cephalosporins on strains of Neisseria gonorrhoeae of the Toulouse region. Chemotherapy 1981;27suppl 1:15-8.

7. Thabaut A, Durosoir JL, Saliou P. Comparative in vitro activity of eight cephalosporins on 109 strains of Neisseria gonorrhoeae and 60 strains of $N$ meningitidis. Chemotherapy 1981;27suppl 1:19-24.

8. Yoshikawa TT, Shibata SA, Herbert P, Oill PA. In vitro activity of Ro 13-9904, cefuroxime, cefoxitin and ampicillin against Neisseria gonorrhoeae. Antimicrob Agents Chemother 1980;18:355-6.

9. Ng WS, Chau PY, Ling J, Echeverria P, Rockhill R, Arnold K. Penicillinase-producing Neisseria gonorrhoeae isolates from different localities in South East Asia: susceptibility to 15 antibiotics British Journal of Venereal Diseases 1983:59:232-6.

10. Handsfield HH, Murphy VL. Holmes KK. Dose ranging study of ceftriaxone for uncomplicated gonorrhoea in men. Antimicrob Agents Chemother 1981;20:839-40.

11. Rajan VS, Sng EH, Thirumoorthy T, Goh CL Ceftriaxone in the treatment of ordinary and penicillinase-producing strains of Neisseria gonorrhoeae. British Journal of Venereal Diseases 1982;58:314-6.

12. Eichmann A, Weidmann G, Havas L. One dose treatment of acute uncomplicated gonorrhoea of male patients with ceftriaxone RO 13-9904, a new parenteral cephalosporin. Chemotherapy 1981;27:suppl 1:62-9.

13. Giamarellou H, Poulopoulos B, Katsabas A, Petrikkos G, Papapetropoulou M, Daikos GK. Antibacterial activity of Ro 13-9904 and preliminary experience in gonorrhoea and chronic urinary tract infections. Chemotherapy 1981;27:suppl 1:70-4.
14. Panikabutra K, Ariyarit C, Chitwarakorn A, Saensanoh C, Wongba $\mathrm{C}$. Randomised comparative study of ceftriaxone and spectinomycin in gonorrhoea. Genitourin Med 1985;61:106-8.

15. Fernex M, Havas L, Ryff JC, Clarke MR. Ergebnisse der klinischen Prufung von Ceftriaxon. In: Grieshaber $\mathbf{R}$, ed. Proceedings of the Hahneklee Simposium 1981. Grenzach, West Germany: Editiones Roche, 1981:389-93.

16. Rufli Th, Beerli Th, Eichmann A, Harder F, Weidmann G. Ermittlung der optimalen Dosierung von Ceftriaxon (Ro 139904) am Beispiel der Gonorrhoe-therapie. In: Grieshaber R, ed. Proceedings of the Hahneklee Symposium 1981; Grenzach, West Germany: Editiones Roche, 1981:205-14.

17. Young H. Cultural diagnosis of gonorrhoea with modified New York City (MNYC) medium. British Journal of Venereal Diseases 1978:54:36-40.

18. Walsh RJ, Scott R, Bittiner JB, Shahidullah M, Slack RCB. Acrosoxacin in the treatment of uncomplicated gonorrhoea. British Journal of Venereal Diseases. 1983;59:242-4.

19. Clay JC, Veeravahu M, Sumathipala ATH. Ceftriaxone in the treatment of uncomplicated gonorrhoea in males and females. European Journal of Sexually. Transmitted Diseases 1985;2:99. 102.

20. Collier AC, Judson FN, Murphy VL, Leach LA, Root CJ, Handsfield $\mathrm{HH}$. Comparative study of ceftriaxone and spectinomycin in the treatment of uncomplicated gonorrhoea in women. Am J Med 1984;77:68-72.

21. Judson FN, Ehret JM, Handsfield HH. Comparative study of ceftriaxone and spectinomycin for treatment of pharyngeal and ano-rectal gonorrhoea. JAMA 1985;253:10,1717-9.

22. Patel $H$, Weinfeld RE, Konikoff J, Parsonnet $M$. Pharmacokinetics and tolerance of ceftriaxone in humans after single-dose intramuscular administation in water and lidocaine diluents. Antimicrob Agents Chemother 1982;21:957-62.

23. Johnson RC, Bey RF, Wolgamot SH. Comparison of the activities of ceftriaxone and penicillin $\mathrm{G}$ against experimentally induced syphilis in rabbits. Antimicrob Agents Chemother 1982;21:984-9.

24. Department of Health and Social Security. On the state of the public health. London: HMSO 1984;56-7.

25. McCutchan JA, Adler MW, Berrie RH. Penicillinase producing Neisseria gonorrhoeae in Great Britain 1977-81: alarming increase in incidence and recent development of endemic transmission. Br Med J 1982;285:337-40. 